\title{
Quantifying the Effect of Metformin 1000 mg/Day in Japanese Patients with Type 2 Diabetes
}

\author{
Katsunori Suzuki*, Taishi Yoshioka, Yoko Wakui \\ Division of Endocrinology and Metabolism, Saiseikai Niigata Daini Hospital, Niigata, Japan \\ Email: ${ }^{*}$ katsu-s@ngt.saiseikai.or.jp
}

Received 14 July 2014; revised 1 August 2014; accepted 10 August 2014

Copyright @ 2014 by authors and Scientific Research Publishing Inc.

This work is licensed under the Creative Commons Attribution International License (CC BY). http://creativecommons.org/licenses/by/4.0/

(c) (i) Open Access

\section{Abstract}

Objective: To examine the effect of high-dose metformin on glucose metabolism in Japanese patients with type 2 diabetes. Method: A total of 144 patients with type 2 diabetes who could be followed up for 6 months after their dose of metformin was increased to $1000 \mathrm{mg} /$ day (from 750 $\mathrm{mg} /$ day or less) were examined. The dose of metformin was increased from $750 \mathrm{mg} / \mathrm{day}$ in 70 subjects (250-mg dose increase) and from $500 \mathrm{mg} /$ day in 74 subjects (500-mg dose increase). Results: After the dose increased to $1000 \mathrm{mg} /$ day, HbA1c was significantly decreased by $0.65 \% \pm$ $0.7 \%, 0.42 \% \pm 0.5 \%$, and $0.87 \% \pm 0.7 \%$ in all subjects, the $250-\mathrm{mg}$ dose increase group, and the 500-mg dose increase group, respectively. No significant change was observed in weight. Analysis by BMI $\left(<25 \mathrm{~kg} / \mathrm{m}^{2}\right.$ and $\left.\geq 25 \mathrm{~kg} / \mathrm{m}^{2}\right)$ revealed a comparable significant decrease in $\mathrm{HbA1c}$ in all subjects, the $250-\mathrm{mg}$ dose increase group, and the 500-mg dose increase group. Analysis by duration of diabetes showed a significant decrease in HbA1c regardless of the duration. Conclusion: Increasing the metformin dose to $1000 \mathrm{mg} /$ day showed a significant antihyperglycemic effect over 6 months in Japanese patients with type 2 diabetes. Blood glucose improved regardless of the duration of diabetes or the presence or absence of obesity. Overall tolerability was favorable.

\section{Keywords}

High-Dose Metformin, Type 2 Diabetes, HbA1c

\section{Introduction}

Metformin, a biguanide, has been used in the treatment of type 2 diabetes since the 1950s. In the 1970s, the ad-

"Corresponding author.

How to cite this paper: Suzuki, K., Yoshioka, T. and Wakui, Y. (2014) Quantifying the Effect of Metformin $1000 \mathrm{mg} /$ day in Japanese Patients with Type 2 Diabetes. International Journal of Clinical Medicine, 5, 894-901. 
verse events of lactic acidosis, which was associated with phenformin, a biguanide, were shown in USA. As a result, restrictions were placed on the dosage and administration method of biguanides in many countries, and it became difficult to use biguanides in Japan. However, in The Multicenter Metformin Study [1] and The UK Prospective Diabetes Study (UKPDS) [2] [3] that have been conducted since the 1990s, metformin, a representative biguanide, lowered blood glucose level primarily through the inhibition of hepatic glucose production without increasing body weight and insulin secretion, and the incidence of adverse events including lactic acidosis was rare, showing its effectiveness and safety. Thus, metformin started to attract attention and became the first-line agent for the treatment of type 2 diabetes in Europe and USA [4] [5]. The antihyperglycemic effect of metformin was dose-dependent, and the maximum effect was obtained at a dose of $2000 \mathrm{mg} /$ day in most patients [6]. For this reason, the maximum recommended daily dose of metformin is $2000 \mathrm{mg} /$ day in the USA and $3000 \mathrm{mg} /$ day in Europe and other countries. Importantly, the metabolic and clinical outcomes for metformin in the UKPDS were obtained using a median daily dose of $2550 \mathrm{mg} /$ day [2]. In contrast, the local regulation had placed an upper limit of daily dose of metformin at $750 \mathrm{mg} /$ day from 1977 to $2010 \mathrm{in}$ Japan.

However, the effectiveness and safety of metformin have recently been confirmed in the Melbin Observational Research (MORE) [7] study conducted in Japan. Moreover, use of high doses of metformin up to $2250 \mathrm{mg} /$ day (Metgluco ${ }^{\circledR}$ tablet $250 \mathrm{mg}$ ) was approved in 2010, which made this drug indispensable in the treatment of diabetes. Nevertheless, with regard to the clinical data on use at high doses, use at a dose of $1500 \mathrm{mg} / \mathrm{day}$ or 2250 $\mathrm{mg} /$ day has been reported only occasionally [8]. In the present study, the antihyperglycemic effect of a metformin dose increase to $1000 \mathrm{mg} /$ day (from $750 \mathrm{mg} /$ day or lower doses) was retrospectively examined in patients with type 2 diabetes. The results were also analyzed by BMI, duration of disease, and concomitant drug use.

\section{Subjects and Methods}

A total of 144 patients with type 2 diabetes (62 men, 82 women; mean age, $58.5 \pm 12$ years; BMI, $26.1 \pm 4.1$ $\mathrm{kg} / \mathrm{m}^{2}$; duration of disease, $11.7 \pm 6.0$ years) who regularly visited the outpatient diabetes clinic of our hospital and could be followed up for 6 months after the metformin dose increase to $1000 \mathrm{mg} / \mathrm{day}$ (from $750 \mathrm{mg} / \mathrm{day}$ or lower doses) (Table 1) was examined. This study was conducted according to the principals expressed in the Declaration of Helsinki Informed consent was obtained from each subject after full explanation of the purpose, nature, and risk of all procedures used. The study protocol was approved by the ethical review committee of Saiseikai Niigata Daini Hospital.

Of these, the dose was increased from $750 \mathrm{mg} /$ day in 70 subjects (250-mg dose increase group) and from 500 $\mathrm{mg} /$ day in 74 subjects (500-mg dose increase group). Patients whose other antidiabetic drugs were changed during the study period, those with serious liver dysfunction, cardiovascular or respiratory diseases, those with a serum creatinine level of $1.5 \mathrm{mg} / \mathrm{dL}$ or higher, and those who regularly consumed excessive amounts of alcohol were excluded from the study. The mean HbA1c (NGSP [National Glycohemoglobin Standardization Program] value) at baseline was $8.2 \% \pm 0.6 \%$. Concomitant drugs were sulfonylureas (SUs) in 69 subjects, insulin in 43 subjects, dipeptidyl peptidase 4 (DPP4) inhibitors in 28 subjects, $\alpha$-glucosidase inhibitors ( $\alpha$ GIs) in 14 subjects, Pioglitazone in 4 subject, glinides in 3 subjects, and none in 26 subjects (Table 1). Complications are shown in Table 1. Approximately half of the subjects had hypertension. During the study period, treatment with existing oral antihyperglycemic drugs was continued, and drugs that would affect blood glucose or HbA1c were not added to the treatment, and the regimens of these drugs were not changed. The obtained data were summarized by mean values and standard deviations. Statistical analysis was performed using SASW Statistics 18 (SPSS Inc., an IBM Company), by paired t-test, Wilcoxon's signed rank sum test, and one-way analysis of variance (ANOVA). A two-sided significance level of 5\% was used. All HbA1c values are shown as NGSP values.

\section{Results}

The dose of metformin was increased to $1000 \mathrm{mg}$ /day in all subjects. HbA1c was significantly decreased by $0.57 \% \pm 0.6 \%$ and $0.65 \% \pm 0.7 \% 3$ months and 6 months after the dose increase, respectively (Figure 1 ). In the 250-mg dose increase and 500-mg dose increase groups, HbA1c was significantly decreased by $0.39 \% \pm 0.4 \%$ and $0.74 \% \pm 0.7 \%$, respectively, 3 months after the dose increase and by $0.42 \% \pm 0.5 \%$ and $0.87 \% \pm 0.7 \%$, respectively, 6 months after the dose increase. Weight, systolic blood pressure, and diastolic blood pressure were changed from $70.29 \pm 13 \mathrm{~kg}$ to $70.0 \pm 14 \mathrm{~kg}$, from $126.0 \pm 12 \mathrm{mmHg}$ to $126.2 \pm 10 \mathrm{mmHg}$, and from $74.8 \pm 11$ mmHg to 75.2 . 
Table 1. Patient background characteristics.

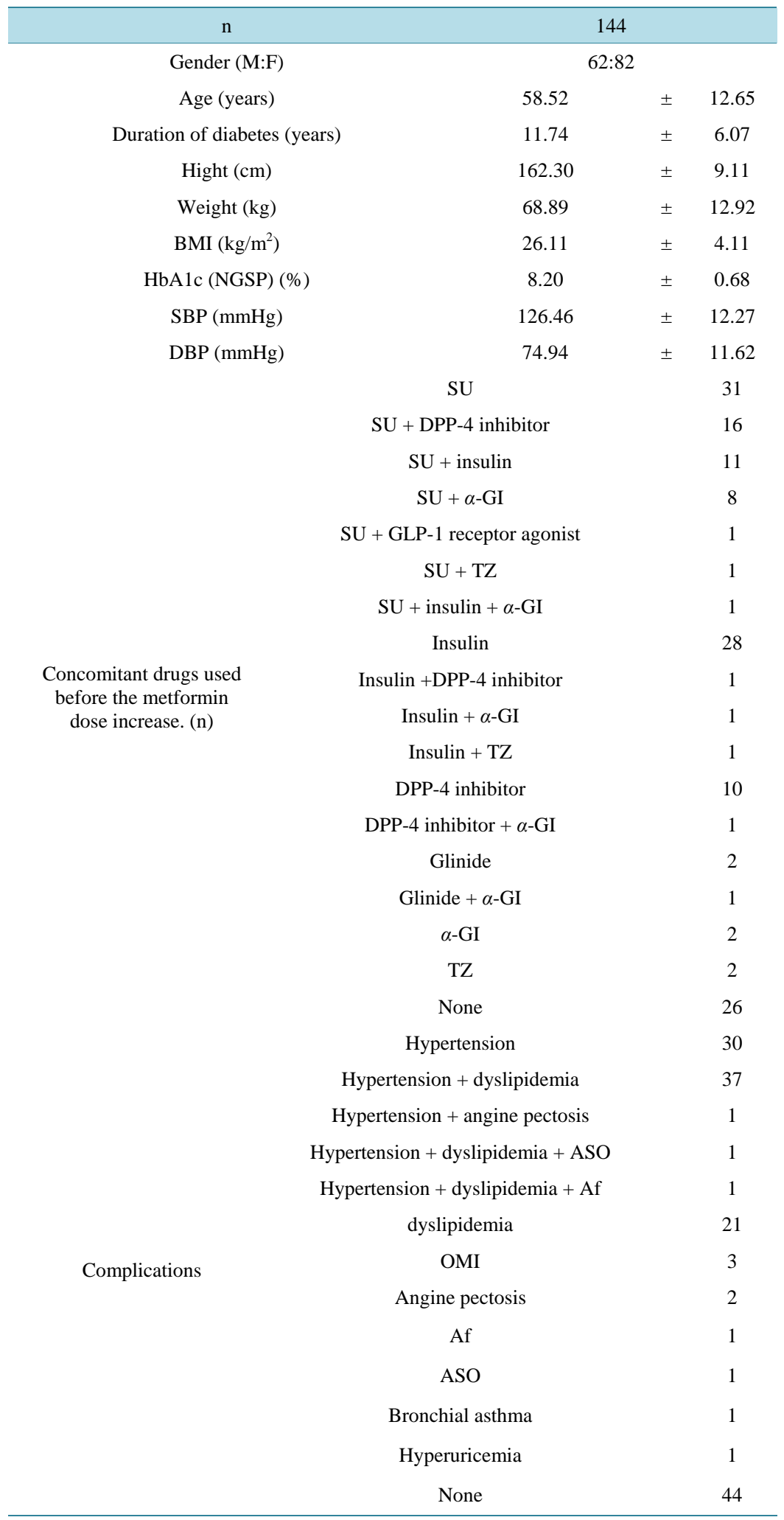

BMI: Body mass index, SBP: systolic blood pressure, DBP: diastolic blood pressure, SU: sulfonylurea, TZ: thiazolidine, DPP-4: Dipeptidyl Peptidase-4, $\alpha$-GI: $\alpha$-glucosidase inhibitor; OMI: old myocardial infarction, ASO: arteriosclerosis obliterans, Af: atrial fibrillations. 


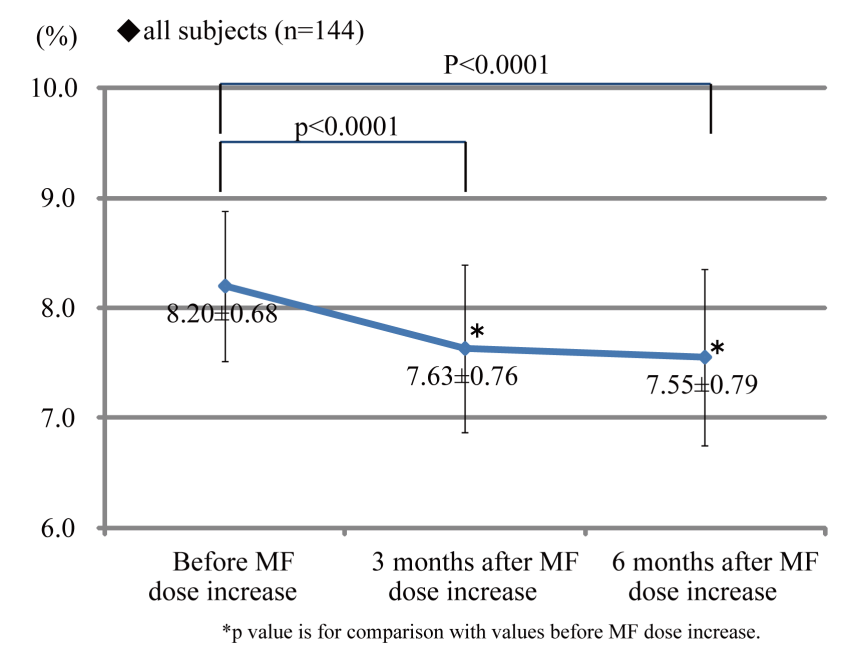

Figure 1. Changes in HbA1c over time in all subjects. * $<0.0001$ vs. values before the metformin dose increase; MF: Metformin.

$\pm 11 \mathrm{mmHg}$, respectively, 6 months after the dose increase; no changes were significant (data are not shown).

Among subjects whose BMI was below $25 \mathrm{~kg} / \mathrm{m}^{2}$, HbA1c was significantly decreased by $0.57 \% \pm 0.5 \%$, $0.38 \% \pm 0.4 \%$, and $0.78 \% \pm 0.5 \%$ in all subjects, the 250 -mg dose increase group, and the 500 -mg dose increase group, respectively, 6 months after the dose increase. Among those with BMI of $25 \mathrm{~kg} / \mathrm{m}^{2}$ or higher, a significant decrease by $0.71 \% \pm 0.8 \%, 0.44 \% \pm 0.6 \%$, and $0.93 \% \pm 0.8 \%$ was observed in all subjects, the 250 -mg dose increase group, and the 500-mg dose increase group, respectively (Figure 2, Figure 3). In each group, the decrease in $\mathrm{HbA} 1 \mathrm{c}$ was greater among subjects with BMI of $25 \mathrm{~kg} / \mathrm{m}^{2}$ or higher.

The decrease in HbA1c by duration of diabetes is shown in Figure 4. The decrease appeared greater in the group with duration of diabetes of 10 years or longer and shorter than 15 years and the group with duration of diabetes of 15 years or longer and shorter than 20 years, but, overall, no significant difference was observed.

The achievement rate of the target HbA1c value of blood glucose control specified in "Treatment Guide for Diabetes 2014-2015" [9], which is below 7\%, was 19.5\% (28/143 subjects). The ratio of subjects whose HbA1c improved more than one level (HbA1c was classified at baseline in the four levels $<6.0 \%, \geq 6.0 \%$ and $<7.0 \%$, $\geq 7.0 \%$ and $<8.0 \%, \geq 8.0 \%$.) was $50.7 \%$ (73/144 subjects) (Figure 5).

The change in body weight caused by the metformin dose increase was examined in the group of subjects treated concomitantly with insulin secretagogues (SUs, glinides) or insulin $(n=114)$, but no significant increase was observed (from $69.49 \pm 14 \mathrm{~kg}$ to $69.38 \pm 14 \mathrm{~kg}, \mathrm{p}=0.50$ ). Although gastrointestinal symptoms including mild diarrhea occurred in only 3 subjects during the follow-up after the dose increase, metformin was not discontinued; it was continued in all subjects. No subject presented with clear hypoglycemic symptoms during the follow-up period.

\section{Discussion}

In Japan, the maximum dose of metformin had been limited for a long time to $750 \mathrm{mg} /$ day, which was a quarter to a third of the maximum dose in the United States and Europe. This gap in metformin dose has been constantly making clinicians wonder whether the evidence regarding metformin in the United States and Europe can be directly used as evidence in Japanese patients.

In the present study, HbA1c was significantly decreased from $8.20 \% \pm 0.6 \%$ to $7.55 \% \pm 0.7 \%$ over 6 months after the metformin dose was increased to $1000 \mathrm{mg}$ /day (from $750 \mathrm{mg} /$ day or lower doses) in 144 patients with type 2 diabetes. Analysis by the level of dose increase showed that the change in HbA1c 6 months after the dose increase was $-0.42 \% \pm 0.5 \%$ in the 250 -mg dose increase group and $-0.87 \% \pm 0.7 \%$ in the 500 -mg dose increase group), indicating a dose-dependent effect that has been pointed out as a characteristic of metformin. This analysis also showed that a dose increase to $1000 \mathrm{mg}$ /day was sufficiently effective even with a 250-mg increase. Garber et al. [6] examined the decrease in HbA1c caused by the metformin dose in patients with type 2 diabetes 


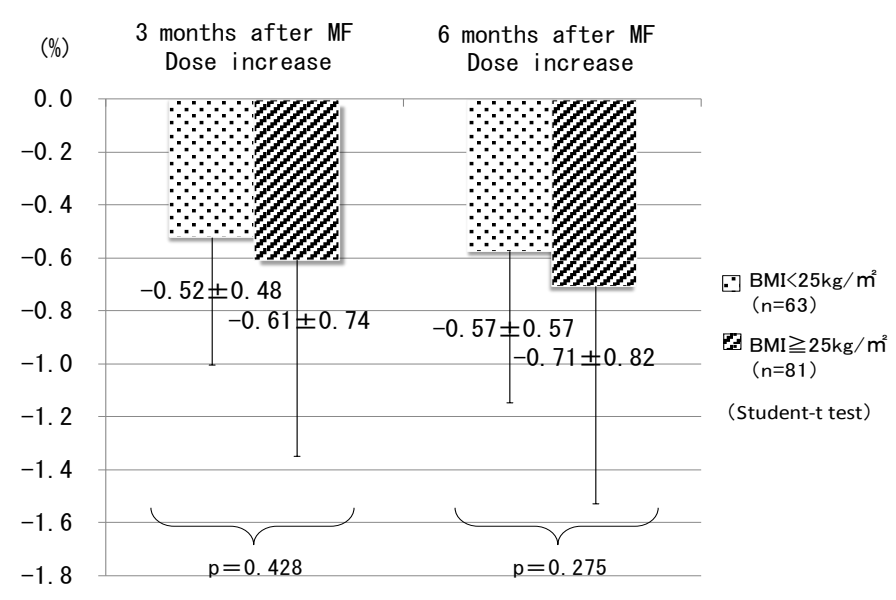

Figure 2. Decrease in HbA1c 3 months and 6 months after the metformin dose increase. There is no significant difference in the change in all subjects, those with BMI $<25 \mathrm{~kg} / \mathrm{m}^{2}$, and those with BMI $\geq 25 \mathrm{~kg} / \mathrm{m}^{2}$. Comparison was performed by Student's t-test.
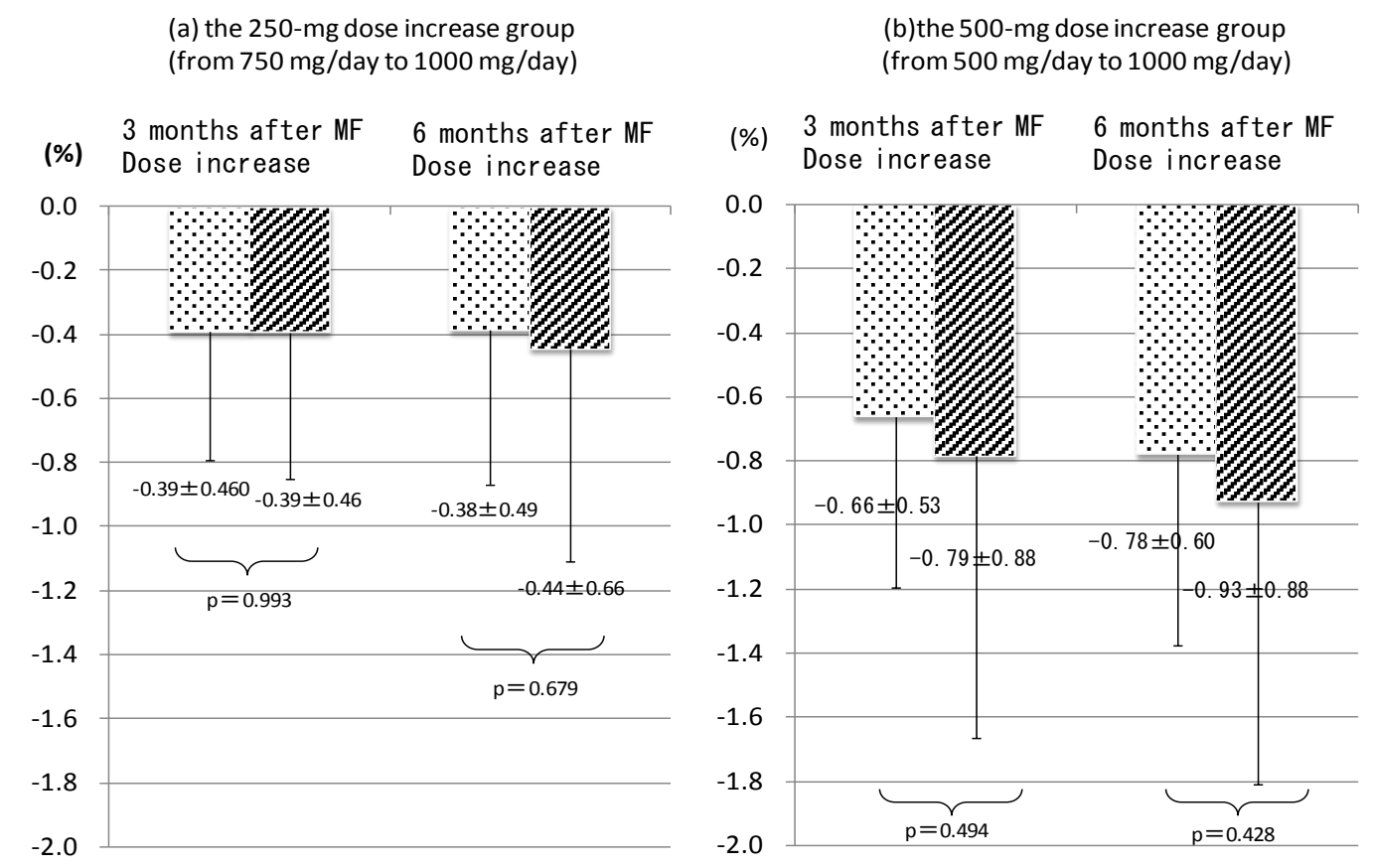

Figure 3. Decrease in HbA1c 3 months and 6 months after the metformin dose increase in the 250-mg dose increase group (from $750 \mathrm{mg} /$ day to $1000 \mathrm{mg}$ /day) and in the 500-mg dose increase group (from $500 \mathrm{mg} /$ day to $1000 \mathrm{mg} /$ day). There is no significant difference in the change in all subjects, those with BMI $<25 \mathrm{~kg} / \mathrm{m}^{2}$, and those with BMI $\geq 25 \mathrm{~kg} / \mathrm{m}^{2}$. Comparison was performed by Student's t-test.

and reported that the change in HbA1c was $-0.3 \%$ to $-0.5 \%$ with 12 -week administration of metformin at a dose of $500 \mathrm{mg}$. Although a direct comparison of this result and the present result $(-0.73 \% \pm 0.7 \%$ in 3 months $)$ would be impossible due to different patient background characteristics and other reasons, it was suggested that Japanese patients are more likely to benefit from the dose-up effect of metformin.

According to the analysis by the presence or absence of obesity, the decrease in HbA1c was somewhat greater in obese subjects (BMI $\geq 25 \mathrm{~kg} / \mathrm{m}^{2}$ ) than in non-obese subjects (BMI $<25 \mathrm{~kg} / \mathrm{m}^{2}$ ) in all subjects, the $250-\mathrm{mg}$ dose increase group, and the 500-mg dose increase group, but no significant differences were observed. The MORE Study [7], a large-scale clinical study of metformin in Japanese subjects, also clearly showed that met- 


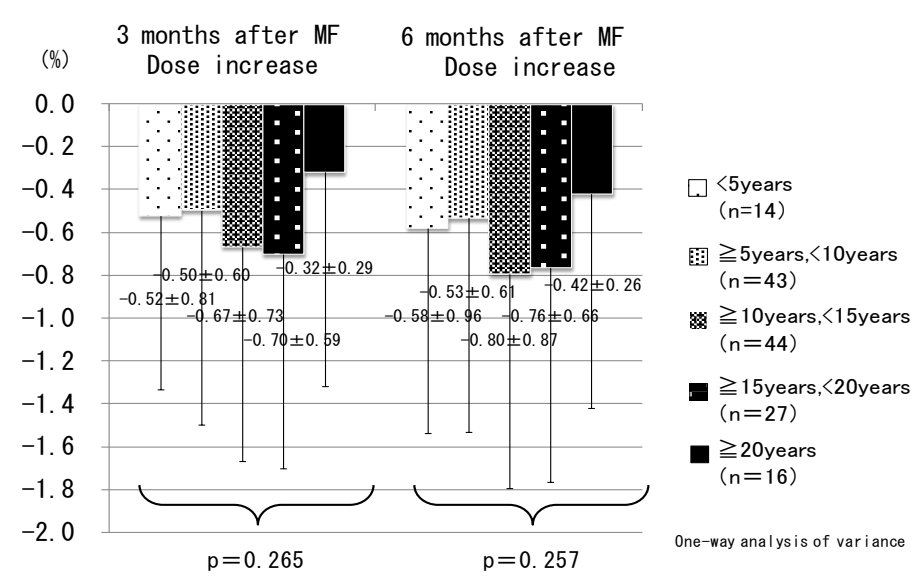

Figure 4. Decrease in HbA1c 3 months and 6 months after the metformin dose increase by duration of diabetes. There is no significant difference in the change in all subjects even if I distributed it in any contraction of duration. Comparison was performed by one-way ANOVA.

\begin{tabular}{|c|c|c|c|c|c|c|}
\hline & \multicolumn{4}{|c|}{ Before dose increase } & \multirow[b]{2}{*}{ Total } \\
\hline & & $\begin{array}{l}\mathrm{HbA} 1 \mathrm{c} \\
\geq 8.0 \% \\
\end{array}$ & $\begin{array}{c}\text { HbA1c } \\
7.0 \%-8.0 \% \\
\end{array}$ & $\begin{array}{c}\text { HbA1c } \\
6.0 \%-7.0 \% \\
\end{array}$ & $\begin{array}{l}\text { HbA1c } \\
<6.0 \% \\
\end{array}$ & \\
\hline \multirow{4}{*}{$\begin{array}{c}\text { After dose } \\
\text { increase }\end{array}$} & $\mathrm{HbA} 1 \mathrm{c} \geq 8.0 \%$ & 29 & 5 & & & 34 \\
\hline & $\begin{array}{c}\text { HbA1c } 7.0 \%- \\
8.0 \% \\
\end{array}$ & 45 & 36 & & & 81 \\
\hline & $\begin{array}{c}\text { HbA1c } 6.0 \% \text { - } \\
7.0 \% \\
\end{array}$ & 9 & 16 & 1 & & 26 \\
\hline & $\mathrm{HbA} 1 \mathrm{c}<6.0 \%$ & 1 & 2 & & & 3 \\
\hline & Total & 84 & 59 & 1 & 0 & 144 \\
\hline
\end{tabular}

Figure 5. Shift in number of patients by HbA1c before and after the metformin dose increase. $(\mathrm{n}=144)$

formin produced antihyperglycemic effects not only in obese patients but also in non-obese patients, and that the level of the effect was comparable. This was confirmed in the present study. Thus, the results of the present study would prompt clinicians to reconsider the fact that they have tended to use metformin only for obese patients.

The analysis by duration of diabetes in this study showed comparable improvement of HbA1c regardless of duration. Because it has been shown in past studies that the longer the duration of diabetes is, the greater the decrease will be in the endogenous capacity to secrete insulin [10], the above result raises the question of why metformin, which is an insulin sensitizer, is effective for patients with long duration of diabetes whose capacity for endogenous insulin secretion is impaired. Metformin acts on the liver, muscles, fat tissue, and other sites in a multifaceted manner, and many actions require insulin. However, for metformin to produce its effects, the insulin concentration does not have to be high. Metformin has been shown to exert effects independent of insulin concentration [11]. This is not the case with thiazolidinediones, which are categorized in the same insulin sensitizer class as metformin. Among its actions, metformin is known to activate AMP kinase, thereby inhibiting cAMP response element-binding protein (CREB)-binding protein (CBP) and CREB regulated transcription coactivator 2 (CRTC2, or transducer of regulated CREB protein 2 [TORC2]), which are transcriptional coactivators, as well as induce glucose-6-phosphatase (G6Pase) and phosphoenolpyruvate carboxykinase (PEPCK), which are the enzymes catalyzing gluconeogenesis and eventually controlling gluconeogenesis [12]. Moreover, a pathway of the actions of metformin that is not mediated by AMP kinase has recently been clarified. In this pathway, metformin at a therapeutic dose increases the concentration of AMP up to the level that is enough to decrease the activity of adenylate cyclase. As a result, cyclic AMP is decreased, and the glucagon signaling that follows is inhibited, leading to inhibition of gluconeogenesis [13]. This mechanism of action also supports the finding of this study that metformin produced an antihyperglycemic effect that was independent of insulin con- 
centration. Thus, metformin is considered to be effective in any stage of diabetes.

When the dose of metformin was increased in the present study involving 115 patients (79.8\%) treated with insulin secretagogues including SUs and glinides or insulin preparations, neither hypoglycemia nor significant increases in weight occurred. For patients being treated with SUs or insulin, as well as $750 \mathrm{mg} /$ day of metformin, whose blood glucose is not sufficiently controlled, the next step in the treatment can be to increase the metformin dose.

The most common adverse events with the administration of metformin are gastrointestinal symptoms. In particular, diarrhea and nausea are observed most frequently. Their incidence varies by report, but it ranges from approximately $6 \%$ to $25 \%$ [14]. Garber et al. examined the tolerability of metformin and reported that the rate of interruption of treatment due to diarrhea with treatment at a dose of $500 \mathrm{mg} /$ day was comparable to the rate with administration of placebo, but it was increased at a dose of $1000 \mathrm{mg} /$ day, and there was no difference in the rate of interruption among $1000 \mathrm{mg} /$ day or higher doses [6]. In the 144 patients examined in the present study, only 3 experienced gastrointestinal symptoms including mild diarrhea after the dose increase. All symptoms were alleviated within 1 week, and the treatment was continued. Thus, metformin showed favorable overall tolerability.

The main limitation of the present study is its retrospective design without parallel control group, which prevents us drawing conclusion about causality. Other limitations are that we described the insulin independent mechanism of metformin effect without data of insulin levels in the present study, and that the relatively small number of patients and short duration of the follow-up period prevent the precise estimate of the effectiveness of the treatment. Large-scale, long-term randomized-controlled studies which evaluate endogenous insulin secretion ability are needed to confirm the findings of our study.

\section{Conclusion}

Based on the above results, an increase in the dose of metformin to $1000 \mathrm{mg} /$ day in patients with type 2 diabetes showed a significant antihyperglycemic effect starting 3 months after the increase, and the effect persisted for 6 months. HbA1c was decreased by $0.42 \%$ with the $250-\mathrm{mg}$ metformin dose increase and by $0.87 \%$ with the 500-mg metformin dose increase, indicating an additive effect. With the dose increase, blood glucose improved regardless of the duration of diabetes and the presence or absence of obesity, and overall tolerability was favorable.

\section{Disclosure}

None of the authors have any potential conflicts of interest associated with this research.

\section{References}

[1] Defronzo, R.A. and Goodman, A.M. (1995) Efficacy of Metformin in Patients with Non-Insulin-Dependent Diabetes Mellitus. The Multicenter Metformin Study Group. The New England Journal of Medicine, 333, 541-549. http://dx.doi.org/10.1056/NEJM199508313330902

[2] UK prospective Diabetes Study (UKPDS) Group (1998) Effect of Intensive Blood-Glucose Control with Metformin on Complications in Overweight Patients with Type 2 Diabetes (UKPDS 34). Lancet, 352, 854-865. http://dx.doi.org/10.1016/S0140-6736(98)07037-8

[3] Holman, R.R., Paul, S.K., Bethel, M.A., et al. (2008) 10-Years Follow-Up of Intensive Glucose Control in Type 2 Diabetes. The New England Journal of Medicine, 359, 1577-1589. http://dx.doi.org/10.1056/NEJMoa0806470

[4] International Diabetes Federation (2005) Glucose Control: Oral Therapy. Global Guideline for Type 2 Diabetes. 35-38,

[5] Nathan, D.M., Buse, J.B., Davidson, M.B., et al. (2008) Management of Hyperglycemia in Type 2 Diabetes: A Consensus Algorithm for the Initiation and Adjustment of Therapy: Update Regarding Thiazolidinediones: A Consensus Statement from the American Diabetes Association and the European Association for the Study of Diabetes. Diabetes Care, 31, 173-175. http://dx.doi.org/10.2337/dc08-9016

[6] Garber, A.J., Duncan, T.G., Goodman, A.M., Mills, D.J. and Rohlf, J.L. (1997) Efficacy of Metformin in type II Diabetes: Results of a Bouble-Blind, Placebo-Controlled, Dose-Response Trial. The American Journal of Medicine, 103, 491-497. http://dx.doi.org/10.1016/S0002-9343(97)00254-4

[7] Kaku, K., Tajima, N. and Kawamori, Y. (2006) Melbin Observational Research (MORE) Study of Metformin Therapy in Patients with Type 2 Diabetes Mellitus. Tonyobyo (Diabetes), 49, 325-331. In Japanese.

[8] Sumintani, S., Morita, S., Utsu, Y., Mukai, K., Miki, S., Sato, B., Nakamura, H. and Kasayama, S. (2012) Effective- 
ness of Metformin and Lifestyle Interventions as an Initial Treatment in Japanese Patients with Observational Study. The Journal of Medical Investigation, 59, 166-173. http://dx.doi.org/10.2152/jmi.59.166

[9] Edited by the Japan Diabetes Society (2014-2015) Treatment Guide for Diabetes. 24-25.

[10] Okuno, Y., Sakaguchi, K., Komada, H., Hashimoto, N., Hirota, Y., Nakamura, T., Ogawa, W. and Seino, S. (2013) Correlation of Serum CPR to Plasma Glucose Ratio with Various Indices of Insulin Secretion and Diseases Duration in Type 2 Diabetes. Kobe Journal of Medical Sciences, 59, E44-E53.

[11] Baily, C.J., et al. (1994) Insulin Requirement for the Antihyperglycaemic Effect of Metformin. British Journal of Pharmacology, 111, 793-796. http://dx.doi.org/10.1111/j.1476-5381.1994.tb14807.x

[12] Zhou, G., Myers, R., Li, Y., Chen, Y., Shen, X., Fenyk-Melody, J., Wu, M., Ventre, J., Doebber, T., Fujii, N., Musi, N., Hirshman, M.F., Goodyear, L.J. and Moller, D.E. (2001) Role of AMP-Activated Protein Kinase in Mechanism of Metformin Action. Journal of Clinical Investigation, 108, 1167-1174. http://dx.doi.org/10.1172/JCI13505

[13] Miller, R.A., Chu, Q., Xie, J., Foretz, M., Viollet, B. and Birnbaum, M.J. (2013) Biguanides Suppress Hepatic Glucagon Signalling by Decreasing Production of Cyclic AMP. Nature, 494, 256-260. http://dx.doi.org/10.1038/nature11808

[14] Bailey, C.J. and Howlett, H.C.S. (2008) Tolerability of Metformin. In: Bailey, C.J., Campbell, I.W., Chan, J.C.N., et al, Metformin: The Gold Standard, John Wiley and Sons Ltd., Chichester, 173-178. 
Scientific Research Publishing (SCIRP) is one of the largest Open Access journal publishers. It is currently publishing more than 200 open access, online, peer-reviewed journals covering a wide range of academic disciplines. SCIRP serves the worldwide academic communities and contributes to the progress and application of science with its publication.

Other selected journals from SCIRP are listed as below. Submit your manuscript to us via either submit@scirp.org or Online Submission Portal.
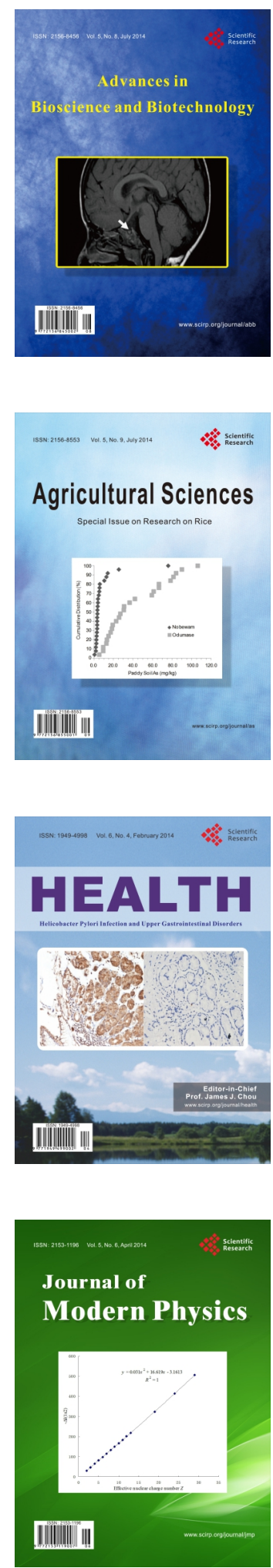
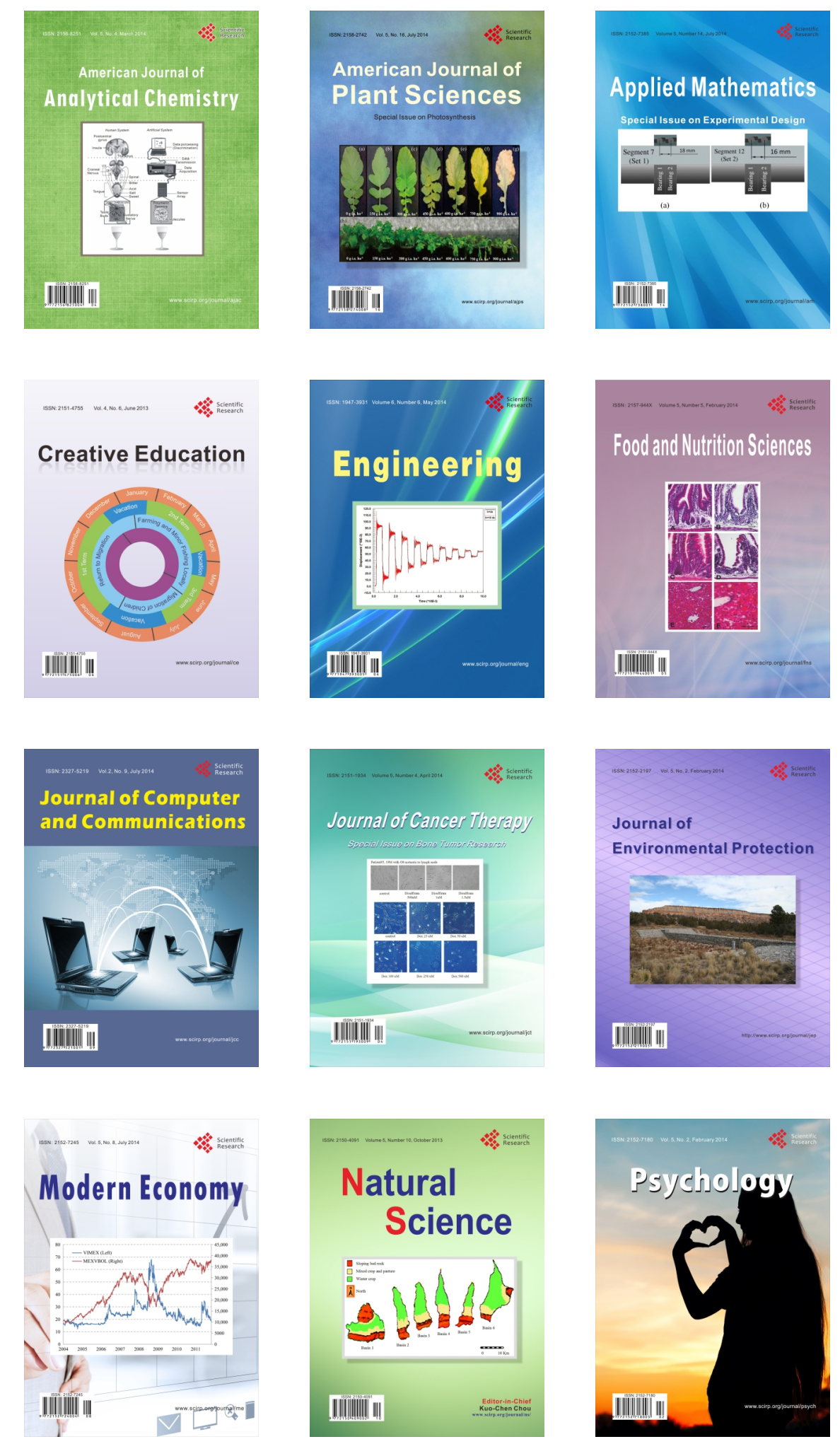